\section{Author Affiliation Addition}

Eric J. Heller's colleagues in the chemistry department of the University of Washington were pleased to read his feature article with Steven Tomsovic on "Postmodern Quantum Mechanics" (July 1993, page 38). During his years in our department Rick made many excellent contributions to our teaching and research programs. (Rick also, it should be noted, held an appointment in the physics department.) In return, the University of Washington supported his efforts generously, particularly in the area of state-of-the-art computing facilities, even in times of significant budget cuts. Indeed the fine color graphics shown in his article, and the basic theory underlying them, were all made possible by the support of our university.

For this reason we were very surprised to find his affiliation given as Harvard University and the Harvard-Smithsonian Center for Astrophysics. Rick took up his appointment in Cambridge on 1 July and we all wish him well in his new position. Right now, Rick is in transition, and members of his research group remain in this department busily using our facilities to study postmodern quantum mechanics. I guess that in the context of Rick's given affiliation "postmodern" must be interpreted as recognizing future employment!

ROBERT O. WATTS Seattle, Washington

\section{Cold Fusion: Still a Hot Research Topic?}

David Williams's review of John R. Huizenga's unrepentantly negative book Cold Fusion: The Scientific Fiasco of the Century (January 1993, page 73) contains disturbing and false assertions. Williams says, "now investigations on so-called cold fusion are confined to only a few laboratories," a claim that is entirely without foundation.

The recent Third International Conference on Cold Fusion in Nagoya, Japan, supported by seven Japanese physical societies and attended by over 350 participants (representing over 70 Japanese companies, universities and institutions), is a stark warning to uninformed "experts" like Williams. At Nagoya there were also over 50 scientific representatives from US corporations and Federal laboratories. Scien- tists who are currently engaged in cold fusion work came to Nagoya from 15 countries. Ya. R. Kucherov from Russia described his remarkable excess-heat results and multiplechannel nuclear product detections in reproducible palladium-deuterium glow discharge experiments. ${ }^{1}$ Cold fusion experiments and theorizing continue at some 24 laboratories in Russia.

Cold fusion research is in fact growing rapidly, not declining, despite Huizenga's and the US Department of Energy's role in branding the phenomenon "pathological science." If Williams (or anyone else) wishes to see the impressive list of attendees at Nagoya and their affiliations, I will gladly mail him the list; it has already been sent to the appropriate high officials in the Clinton Administration and in Congress who may influence energy research policy. Moreover, Williams cannot be unaware of the Japanese Ministry of International Trade and Industry's cold fusion program, which was formally initiated last year.

Williams says that Huizenga "reserves some of his best polemic" for the cold fusion theorists "who seemed to crawl out of the woodwork." Are we to understand that theorizing about mysterious phenomena is not an integral part of physics?

Williams says that public presentations on the topic of cold fusion "tend to fudge experimental details." What presentations is he writing about? $\mathrm{He}$ did not attend either the first (Salt Lake City), second (Como, Italy) or third international conferences on cold fusion. Who is Williams to lecture cold fusion researchers for their "fail[ure] to distinguish .... what is real from what is imaginary," when he has been nearly completely disengaged from the field since 1989? As Williams knows, his own 1989 Harwell experiments, which supposedly failed to confirm cold fusion, are currently being reviewed by several researchers who are experienced in signal processing of timeseries calorimetric data. One study of the Harwell data has already been published in the proceedings of the Third International Conference on Cold Fusion, and it shows that excess heat was in fact measured in at least one of the Harwell cells in ten time intervals. $^{2}$

Miraculously, Williams's apparent lack of involvement in cold fusion research has not prevented him from discovering what the cold fusion phenomenon really is! Williams ends his review: "There may in fact exist in the palladium-hydrogen system, under circumstances that remain ill de- fined, a release of stored energy as heat. ... But what profit is there in such an inefficient, unreliable, dangerous and expensive energy storage method?" In this remark he is only one degree better than Huizenga, who has recently written, "At best, the cold fusion fiasco may lead to new information in electrochemistry, but even this has not been established" (italics added). ${ }^{3}$

Now if cold fusion is merely an "energy storage method," how are we to understand the published SRI International results, ${ }^{4}$ which indicate a fantastic "energy storage" in palladium of $45.1 \mathrm{MJ} / \mathrm{mole}$ of $\mathrm{Pd}$ atoms? This obviously seems to be far beyond what can be explained by any known chemical bonding mechanism. The PonsFleischmann repeatable boiling cell experiments, in which tens of milliliters of heavy water are totally evaporated within 10-30 minutes, exhibit "storage" energies on the order of $200 \mathrm{eV}$ per atom in the boil-off phase alone. It is not uncommon these days for cold fusion researchers to demonstrate excess energy releases that would require "storage" on the order of $20000 \mathrm{eV}$ per cathode atom.

The cold fusion phenomenon, in the view of many active in the field, is a spectacular new form of latticeinduced nuclear energy whose mechanism is still poorly understood-as the mechanism of low-temperature superconductivity was for many decades. That the nuclear products that have been found so far are incommensurate (by conventional theory) with the non-chemical-magnitude excess energies simply means that the results have to be explained by new physical mechanisms. It matters not at all to nature that the American Institute of Physics's journalistic publications refuse to comprehend this, but it matters a great deal to our economic well-being.

It will be deliciously amusing to see many US physicists, who are now so negative, run pork-barreling fast to the trough of cold fusion fundingboth private and (hopefully) Federal-after the complete triumph of this startling new phenomenon and source of energy.

\section{References}

1. A. B. Karabut, Ya. R. Kucherov, I. B. Savvatimova, Phys. Lett. A 170, 265 (1992).

2. M. E. Melich, W. N. Hansen, in Frontiers of Cold Fusion, H. Ikegami, ed., Universal Academic, Tokyo (1993), p. 397.

3. J. R. Huizenga, Leaders, January-February-March 1993, p. 23.

4. M. C. H. McKubre, R. Rocha-Filho, S. I. Smedley, F. L. Tanzella, S. CrouchBaker, T. O. Passell, J. Santucci, in The Science of Cold Fusion, Proc. II Annu. 
Conf. on Cold Fusion, T. Bressani, E. Del Giudice, G. Preparata, eds., Italian Phys. Soc., Bologna (1991), p. 419.

Eugene Mallove

Bow, New Hampshire

Williams REPLIES: Eugene Mallove seeks to twist the fact of the review of our results ${ }^{1}$ by others to support his own point of view. The facts are these: Some time ago, I was asked whether our raw calorimetric data could be made available for review, along with data from other laboratories. One justification for such a review was the availability of newly developed methods of data analysis. Another was that such a review might highlight differences that could explain the apparently conflicting results. The raw data, and access to all extant records at the Harwell Laboratory concerning "cold fusion," were freely provided in the interest of promotion of scientific discussion. The review is now proceeding; when it is finished, the results will, I hope, be published. The premature publication of a selected aspect of a part of the review merely highlights that there are matters for debate; given the uncertainties in the PonsFleischmann form of calorimetry addressed, this is hardly surprising.

Mallove also repeats the common assertion that the excess energies associated with the electrolysis of $\mathrm{D}_{2} \mathrm{O}$ with a Pd cathode are on the order of tens to hundreds of $\mathrm{MJ} / \mathrm{cm}^{3}$ and hence can only find an explanation in some phenomenon outside the chemistry of the system. In this he displays an ignorance of the experimental measurement and a naive belief in the significance of impressively large numbers. The great majority of experiments measure power; the large numbers are obtained by multiplying an (often small) power by a large time (the duration of the experiment) and dividing by a small volume (that of the $\mathrm{Pd}$ cathode). In comparison with the total energy applied to the electrolytic cell, the excesses are much less impressive, on the order of a few percent. More properly, in comparison with the power applied to the cell, the claimed excess power is often also small, although the claims vary greatly and seem to me to be dependent on the calorimetric method used; hence the intense discussion of the accuracy of electrochemical calorimetry, the errors introduced and corrections required as a consequence of using different types of instrument, and the efforts to improve the measurement. The SRI International researchers, whom Mallove quotes selectively, clearly address this question in their presentations of their results. There is no doubt that the methodology of electrochemical calorimetry has been considerably advanced as a consequence of the investigations into "cold fusion," and it is a pity that this achievement (which has resulted in negative as well as positive claims, though Mallove would choose to ignore the former) is not properly recognized: I would anticipate its bearing fruit in unexpected ways in the future. As for the occurrence of thermal excess phenomena in the Pd-D system, healthy skepticism remains, in my view, the proper approach, not to be disturbed by dubious claims of untold megajoules of energy such as are uncritically parroted by Mallove.

Mallove also plays the numbers game with laboratories confirming results and conference attendees. Indeed, I am sent such lists as evidence for the wrongheadedness of my views. Unfortunately, my brush with the experimental facts of "cold fusion" has left me unashamedly skeptical, and John R. Huizenga's dispassionate dissection of the many and varied claims confirmed me in that position. Mallove takes me to task for complaining that there is a failure, in the literature claiming "cold fusion," to distinguish what is real from what is imaginary, and that there is a tendency to fudge experimental details. The fact is that I cannot resolve the discordance between the positive claims that I read and my own experimental experience; naturally, I look to this literature to tell me what I did "wrong," but I fail to find any satisfactory answer. As far as I can tell, Mallove's own experimental experience of "cold fusion" in particular, and electrochemistry in general, is minimal. The measurements, both of heat and of nuclear products, are not straightforward. It is very easy to obtain "positive" results, and the lower the levels claimed, the easier it becomes: In fact, the claimed effects, certainly as regards neutron emission and also, as far as I can make out, the heat (stripped of spurious multiplication like that beloved of Mallove), have declined markedly since the original publications.

Enthusiasts claim many different forms of "cold fusion": Every combination of the four indicators (heat, tritium, neutrons, helium) has been claimed, at wildly different levels. Enthusiasts make a big splash, claiming that a reformulation of nuclear physics-apparently different for every claim - is necessary to accommodate a range of startling new phenomena that will revolutionize energy supplies. Yet many of the data on which these claims are based have turned out, as Huizenga illustrates, to be (often literally) just "noise." Only when the "noise," unfortunately overamplified by publicists such as Mallove, is cleared out will it be evident whether there is any "signal" at all, and only when that is established can one start to speculate on whether we are indeed faced with some phenomenon requiring explanation and not just an overenthusiastic overinterpretation of uncertain results.

\section{Reference}

1. D. E. Williams et al., Nature $\mathbf{3 4 2}, 375$ (1989).

David E. Williams University College London $9 / 93$ London, United Kingdom

Huizenga REPLIES: Eugene Mallove attempts to convince readers that a large number of scientists, representing numerous institutions, are currently performing successful cold fusion experiments. This belief of advocates that the evidence supporting cold fusion is now much better than it was in 1989 is a myth. Mallove is unduly impressed by his various counting analyses of the participants at the Third International Conference on Cold Fusion, held on 21-25 October 1992 in Nagoya, Japan (and in any event his tally of scientists from US corporations and Federal laboratories is too large). In any case, it is not important how many scientists and laboratories are working on cold fusion; what matters is whether even one group has provided convincing, reproducible evidence. And once one delves beyond the attendance statistics at Nagoya, the conference offered no convincing evidence to support the existence of any room temperature nuclear reaction process producing watts of excess heat. Hence my evaluation of that conference directly contradicts that of Mallove.

Even so, one must acknowledge that numerous bizarre and exotic claims have been added to the cold fusion saga in recent years. ${ }^{1}$ As an example of the more recent claims, several groups are now reporting enormous amounts of excess heat from electrolytic cells containing light-water (that is, $\mathrm{H}_{2} \mathrm{O}$ as opposed to $\mathrm{D}_{2} \mathrm{O}$ ) solutions and nickel cathodes. Randell L. Mills and Steven P. Kneizys $^{2}$ have reported a power gain of several hundred percent when using $\mathrm{K}_{2} \mathrm{CO}_{3}$ as the electrolyte; with $\mathrm{Na}_{2} \mathrm{CO}_{3}$, they obtain no excess power. These authors claim the excess heat has a chemical origin due to the relaxation of hydrogen to a new, 
shrunken electronic orbit. Others, ${ }^{3}$ however, have reported that $\mathrm{Na}_{2} \mathrm{CO}_{3}$ cells give "about twice the excess power as a comparable $\mathrm{K}_{2} \mathrm{CO}_{3}$ cell" and promote an "alkali-hydrogen fusion" process (ignoring the large Coulomb barrier). Some researchers ${ }^{4}$ have even reported large yields of tritium from such light-water electrolysis experiments. As is true of so many cold fusion claims, the lightwater reports are riddled with inconsistencies, contradictions, experimental uncertainties, inadequate controls and improper assessment of errors.

Mallove also mentions what he calls the "remarkable... results" of Ya. R. Kucherov and coworkers. ${ }^{5}$ These Russian researchers have reported excess heat and a wide array of nuclear reaction products, including charged particles of many different energies up to a maximum energy of $18 \mathrm{MeV}$, neutrons with energies up to $17 \mathrm{MeV}$, gamma rays and $\mathrm{x}$ rays of several energies, many radioactive and stable nuclides, and palladium fission fragments. (The energy threshold for palladium fission is several tens of MeV.) Their reported excess heat was three orders of magnitude larger than the summed energies of all reaction products. There is, however, a more serious discrepancy. No major Russian (or other) laboratory with expertise in nuclear physics that has attempted to reproduce these experiments has been successful.

From the standpoint of verification of cold fusion, the Third International Conference was a colossal failure. After 43 months of effort, there was still not a single report at that conference of a definitive, reproducible experiment producing commensurate amounts of excess heat and nuclear reaction products. Mallove dismisses the necessity of this equivalence by stating that "the results have to be explained by new physical mechanisms." Mallove himself has coauthored one of these "new" theories, ${ }^{6}$ which "explains" why "the nuclear reaction products inside cold fusion cells" are not "commensurate with the excess heat." Mallove theorizes that the product helium nuclei are formed with enormous energies and mostly escape from the cell. In concocting this miraculous feat, Mallove violates time-honored conservation laws. Under the umbrella of cold fusion in metallic lattices, any nuclear reaction is assumed to be feasible!

In contrast to Mallove's declaration that cold fusion is a "spectacular new form of lattice-induced nuclear energy," I conclude that there is no persuasive evidence to support this far-out claim. Instead, cold fusion as a nuclear process producing watts of excess heat is more likely than not to be an example of pathological science.

\section{References}

1. These are discussed in my new paperback, J. R. Huizenga, Cold Fusion: The Scientific Fiasco of the Century, Oxford U. P., New York (1993).

2. R. L. Mills, S. P. Kneizys, Fusion Technol. 20,65 (1991); testimony before Subcommittee on Energy of the House Committee on Science,Space and Technology,5May 1993.

3. For example, R. T. Bush, Fusion Technol. 22, 301 (1992); see also R. T. Bush, R. D. Eagleton, in Frontiers of Cold Fusion, Proc. Third Int. Conf. on Cold Fusion, H. Ikegami, ed., Universal Academy P., Tokyo (1993), pp. 405, 409.

4. M. Srinivasan et al, in Frontiers of Cold Fusion, Proc. Third Int. Conf. on Cold Fusion, H. Ikegami, ed., Universal Academy P., Tokyo (1993), p. 123.

5. A. B. Karbut, Ya. R. Kucherov, I. B. Savvatimova, Phys. Lett. A 170, 265 (1992); in Frontiers of Cold Fusion, Proc. Third Int. Conf. on Cold Fusion, H. Ikegami, ed., Universal Academy P., Tokyo (1993), p. 165.

6. R. A. Brightsen, E. F. Mallove, submitted to Fusion Technol., 9 August 1992.

JOHN R. HUIZENGA

$9 / 93$

University of Rochester Rochester, New York

Including the review of John R. Huizenga's book, most of the many publications that have appeared on "cold fusion" since the experiments by Stanley Pons and Martin Fleischmann at the University of Utah were announced have been marked by a curious omission. At least some of the writers must know that in 1926 the distinguished radiochemist Fritz Paneth carried out experiments nearly identical to those of the Utah group, except that deuterium had not yet been discovered, so Paneth used ordinary hydrogen. That aside, he made specific attempts to verify the conversion of hydrogen into helium. He reported success ${ }^{1}$ based on finding helium after sending electricity through hydrogenladen palladium and palladized asbestos, only to retract his conclusions shortly afterward. ${ }^{2}$ A report on Paneth's original claim was briefly mentioned by Barbara Goss Levi in her report on cold fusion in PHYSICS TODAY (June 1989, page 19).

Paneth had carefully outgassed his samples before subjecting his materials to the electric discharge, but then realized that he had not actually depleted his apparatus of all the trapped helium. It should be remembered that thanks to the transmutations revealed by the still novel phenomenon of radioactivity, people in those days claimed they could make various conversions of one element into another. Those investigators weren't (all) quacks; they included
Nobel chemistry laureate William Ramsay, who, among other things, "made" argon via the electron bombardment of sulfur. ${ }^{3}$ He had earlier "made" helium, a result initially "confirmed" by others. Equally remarkable claims, such as the conversion of mercury into gold, were made by others. ${ }^{4}$ Following Paneth's reports, but based on independent research, the Swedish refrigeration engineer John Tandberg tried (but failed) to patent cold fusion as a method of making helium. It was primarily Ernest Rutherford who put a stop to that conversion nonsense by remarking that in all the assorted cases, the appearance of an element had been mistaken for its creation. ${ }^{5}$

The Utah work had a feature that also has seemingly been overlooked by various writers on the subject. It apparently took several weeks before the Pons-Fleischmann equipment began to function. That delay may be accounted for as follows: Pons and Fleischmann, like Paneth, carefully outgassed their apparatus prior to applying any voltage, thus removing any superficial helium present $a b$ ini. tio on their substances and containers. However, as time passed, it is probable that deep-lying helium made its way to the surface, leading to its detection. That helium was then attributed to a magically enhanced tunneling process. This scenario would account for the time delay and for the absence of the tritium or neutrons that would certainly accompany any real nuclear events involving the fusion of deuterons.

One might conclude from this account that before one takes startling results at face value, one should at least study the history of the subject, for it may truly be said that there is nothing new under the sun.

\section{References}

1. F. Paneth, K. Peters, Naturwissenschaften 14, 956 (1926); Ber. Dtsch. Chem. Gesellschaft 59B, 2039 (1926).

2. F. Paneth, K. Peters, G. Paul, Ber. Dtsch. Chem. Gesellschaft 60B, 808 (1927). F. Paneth, Naturwissenschaften 15, 379 (1927); Nature 119, 706 (1927).

3. See M. W. Travers, A Life of Sir William Ramsay, Edward Arnold, London (1956).

4. H. Nagaoka, Naturwissenschaften 13 , $68 Z$ (1925). A. Mietke, H. Stammreich, Z. Anorg. Allg. Chem. 150, 350 (1926); Ber. Dtsch. Chem. Gesellschaft 59B, 359 (1926)

5. E. Rutherford, J. Chadwick, C. D. Ellis, Radiations from Radioactive $\mathbf{S u b}$. stances, Cambridge U. P., Cambridge, England (1930).

STANLEY BASHKIN

University of Arizona

$2 / 93$

Tucson, Arizona 